\title{
Paisajes discordantes. La crisis de la valoración patrimonial y una realidad en contravía ${ }^{1}$ Discordant landscapes. The crisis of the patrimonial valuation and a reality in contravia
}

\author{
Arq. Mg. Alonso Gutiérrez-Aristizábal \\ Facultad de Arquitectura - Universidad La Gran Colombia
}

Fecha de recepción: 10 de abril de 2019

Fecha de aceptación : 30 de abril de 2019

Favor citar este artículo de la siguiente forma:

Gutiérrez-Aristizábal, A. (2019). Paisajes discordantes. La crisis de la valoración patrimonial y una realidad en contravía. AULA Revista de Humanidades y Ciencias Sociales. Vol.64. Número 4, enero-junio 2019. Santo Domingo: Amigo del Hogar. http://dx.doi.org/2636.2236/AULA.2019.004

\section{RESUMEN}

En el contexto de un mundo cada vez más globalizado, que afecta en particular las ciudades de América Latina y que está orientado, entre otras cosas, a homogeneizar las prácticas de consumo, los bienes patrimoniales (materiales e inmateriales) son transformados en mercancía que añade valor a las ciudades que deben responder a la demanda por el interés que despiertan para el turismo internacional y para la sobrevivencia de algunas economías locales. Las acciones que se toman desde las instancias gubernamentales para la gestión del patrimonio tienden a ver sus valores desde una perspectiva instrumentalista que en la mayoría de los casos no considera las verdaderas necesidades de la población que habita estos lugares generando procesos de gentrificación o tomado acciones donde se tiende a petrificar las prácticas y a que se impongan simulacros orientados a complacer las expectativas de los turistas ávidos de consumir «cultura». La valoración, por tanto, requiere de visones más amplias donde se tenga una aproximación holística del territorio. En este sentido, la noción de paisaje contribuye a este propósito. Sin excluir otros tipos de valoración, la comprensión de un lugar patrimonial, desde esa noción de paisaje, permite abordar el problema desde diferentes aspectos y lograr un mejor reconocimiento para la planificación con el fin de poder tomar acciones de mayor pertinencia en la gestión de estos lugares.

Palabras clave: paisaje, paisaje urbano, unidades de paisaje, valoración patrimonial, patrimonio.

\begin{abstract}
In the context of an increasingly globalized world, which affects in particular the Latin American cities and is oriented, among other things, to homogenize consumption practices, heritage (material and inmaterial) assets are transformed into merchandise that adds value to the cities. They must respond to the demand by the interest they arouse for international tourism and for the survival of some local economies. The actions that are taken from the governmental instances for the management of the patrimony tend to see their values from an instrumentalist perspective that in the majority of the
\end{abstract}


cases does not consider the true necessities of the population that inhabits these places, generating gentrification processes or taking actions where there is a tendency to petrify the practices and to impose simulations aimed at satisfying the expectations of tourists eager to consume «culture». Valuation, therefore, requires broader visions where there is a holistic approach to the territory. In this sense, the notion of landscape contributes to this purpose. Without excluding other types of assessment, the understanding of a heritage site from that notion of landscape allows us to approach the problem from different aspects and achieve a better recognition for planning in order to be able to take more relevant actions in the management of these places.

Keywords: Landscape, urban landscape, landscape units, heritage valuation, heritage.

\section{Introducción}

En las condiciones actuales se hace cada vez más evidente la necesidad de posicionar las ciudades latinoamericanas en los mercados culturales, turísticos y tecnológicos mundiales con el fin de lograr algún reconocimiento haciendo evidentes sus procesos urbanos de transformación y mejora en sus equipamientos. ${ }^{2}$ Este interés tiene su origen en los discursos de la globalización, donde temas relacionados con la competitividad, la equidad y la sostenibilidad se plantean como los ejes que sirven de soporte para vender una imagen de ciudad. Muchas de estas ciudades adelantan importantes operaciones urbanas para lograr ese propósito construyendo nuevos paisajes urbanos a partir de diferentes tipos de intervenciones: espacios públicos de grandes dimensiones, centros culturales, museos o complejos donde se mezclan diferentes usos como hoteles, vivienda, comercio y actividades empresariales van transformando las ciudades con el fin de re-densificar, re-cualificar o renovar sus estructuras urbanas; palabras de uso frecuente en los discursos de los políticos y los entes encargados de la planificación territorial.

En este panorama, el tema patrimonial emerge como uno de los de mayor atención y preocupación debido a las amenazas, tensiones y vulnerabilidad con relación a esas grandes operaciones inmobiliarias y en particular, a que su protección está sujeta a la instrumentalización de unas normas que cuando se las revisa en detalle, presentan inconsistencias, vacíos y en algunos casos poca claridad conceptual con relación a la valoración de los bienes que se pretende conservar. Este hecho, es reflejo de un tipo de planificación que asume la conservación patrimonial únicamente como un problema de formulación y aplicación normativa. Es claro que la norma por sí sola no garantiza la conservación de un bien y menos, ilustra sobre su importancia o pertinencia para una sociedad. ${ }^{3}$ El patrimonio urbano y arquitectónico adquiere sentido en la medida en que un grupo social, una comunidad o un individuo lo transforman en referente de su memoria histórica y cuyo fin apunta a que permanezca como testigo del paso del tiempo o como producto de un sueño común que desde el pasado tiene efectos en el presente. Un edificio o sector patrimonial sin un contexto socio cultural que lo dote de sentido desaparece de la memoria colectiva. Por tanto, una norma que actúa únicamente sobre el objeto, sin considerar a las comunidades que habitan los lugares patrimoniales, tiene efectos contradictorios en el paisaje urbano a preservar y en algunos casos produce un efecto inverso al convertir los sectores de interés patrimonial en un simulacro, bajo la premisa de una pretendida recuperación de una tradición o de un hecho colectivo del pasado. (Imagen 1)

Una de las muchas particularidades que caracteriza a la ciudad latinoamericana actual es la de lo imprevisible, que va acompañada de prácticas socioculturales que se expresan de diferentes maneras: se percibe en las tribus o grupos sociales que se mueven por la ciudad dejando huellas mediante el uso de grafías ${ }^{4}$ o haciendo reuniones esporádicas en lugares específicos 


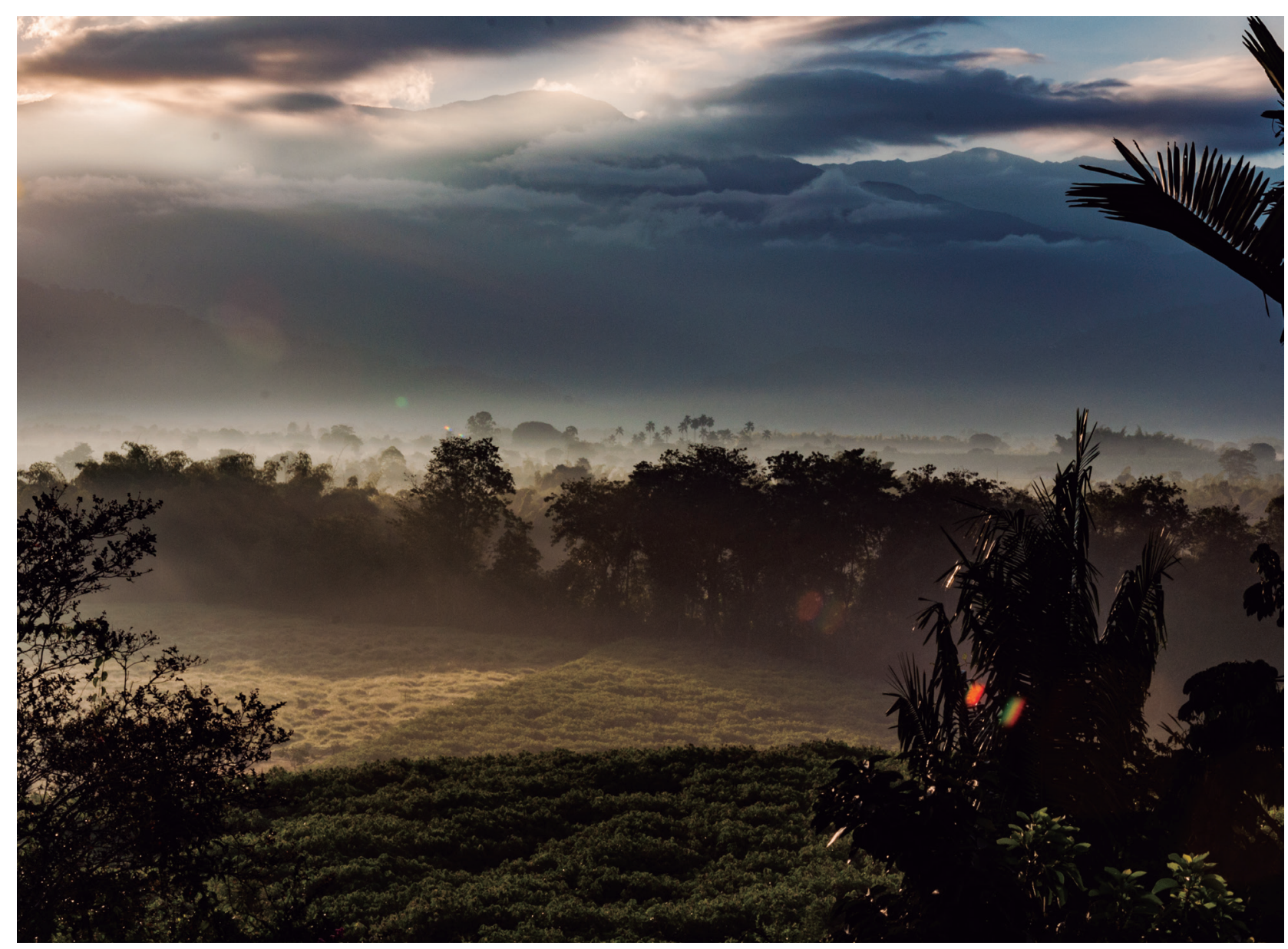

Imagen 1. Amanecer en el paisaje cultural cafetero en Colombia. Declarado patrimonio de la humanidad por la Unesco.

para compartir aficiones comunes; en el espacio público con una relación ambivalente donde la interacción social que pretende construir ciudadanía, promoviendo valores y comportamientos basados en el respeto y la convivencia, se enfrenta en muchos casos con lo amenazante y peligroso de algunos lugares públicos; en convocatorias hechas por las redes sociales para realizar protestas, acciones sociales o celebraciones. También para responder a requerimientos de carácter oficial donde se necesita de la participación ciudadana con fines políticos. Lo imprevisible se manifiesta igualmente interviniendo el patrimonio en algunos sectores declarados de interés patrimonial con unos resultados que son de difícil interpretación y con un efecto inmediato en el paisaje urbano. Esta situación pone de manifiesto la necesidad de contar con sistemas de interpretación y valoración que junto a las aproximaciones conocidas permitan una mayor comprensión para el manejo y conservación de los lugares patrimoniales.

La presente reflexión aborda dos dimensiones específicas, una crítica, en tanto reconoce los sectores de interés patrimonial como hechos colectivos que expresan o reflejan las contradicciones en la aplicación de las políticas públicas junto con la normativa, y otra de tipo propositivo, que pretende reconocer la noción de paisaje ${ }^{5}$ como una herramienta que enriquezca y aporte a la valoración patrimonial. Así mismo, se ha planteado como una herramienta para el trabajo desde el aula en los procesos de análisis en el área de proyecto arquitectónico para que los estudiantes logren un mejor acercamiento a los problemas de la ciudad contemporánea. 


\section{Paisajes contradictorios}

Entre las diferentes acciones que vienen operando como mecanismos reguladores para proteger el patrimonio material e inmaterial se encuentran aquellas que provienen de organismos como la Unesco. La determinación para una declaratoria pasa por muchos filtros y debates apuntando a que exista un consenso en cuanto a la pertinencia para su valoración y sobre todo a su sostenibilidad. Esta acción sobre un lugar, representado en la declaratoria, sobrevalora sus bienes y centra la atención sobre sus productos. Esto abarca un rango amplio de hechos patrimoniales que van desde lo construido hasta lo artesanal. Todos ellos se convierten en una mercancía cultural problemática y de difícil análisis; lo construido, porque tiende a trasformar el paisaje en una escenografía y a sus edificaciones en cascarones, ${ }^{6}$ la artesanía porque pasa de ser producto de una tradición y un saber hacer a objeto masificado y en serie para el consumo turístico. Estas dos situaciones también tienen un impacto en las comunidades que modifican sus patrones de comportamiento para parecer lo que los visitantes esperan que ellos sean. La naturalidad del hacer común y sus relaciones francas de comunidad desaparecen en tanto emergen simulacros de actividad para el goce turístico

En el caso colombiano existen algunos instrumentos para intervenir los sitios patrimoniales o de interés cultural que se encuentran articulados dentro de los Planes de Ordenamiento Territorial y de los Planes Estratégicos de Desarrollo. Los Planes Especiales de Manejo y Protección PEMP permiten estructurar acciones específicas que apuntan a re-funcionalizar los lugares patrimoniales en el marco de las políticas públicas y los planes de desarrollo, tanto a nivel local como nacional. Sin embargo, algunos componentes de estos planes no parecieran comprender la realidad de la vida actual dentro de la situación específica de una comunidad con unos intereses que ya no se encuentran en la tradición sino bajo la presión del mundo globalizado. ¿Cuál es el interés real de las nuevas generaciones? ${ }^{7}$ ¿En qué

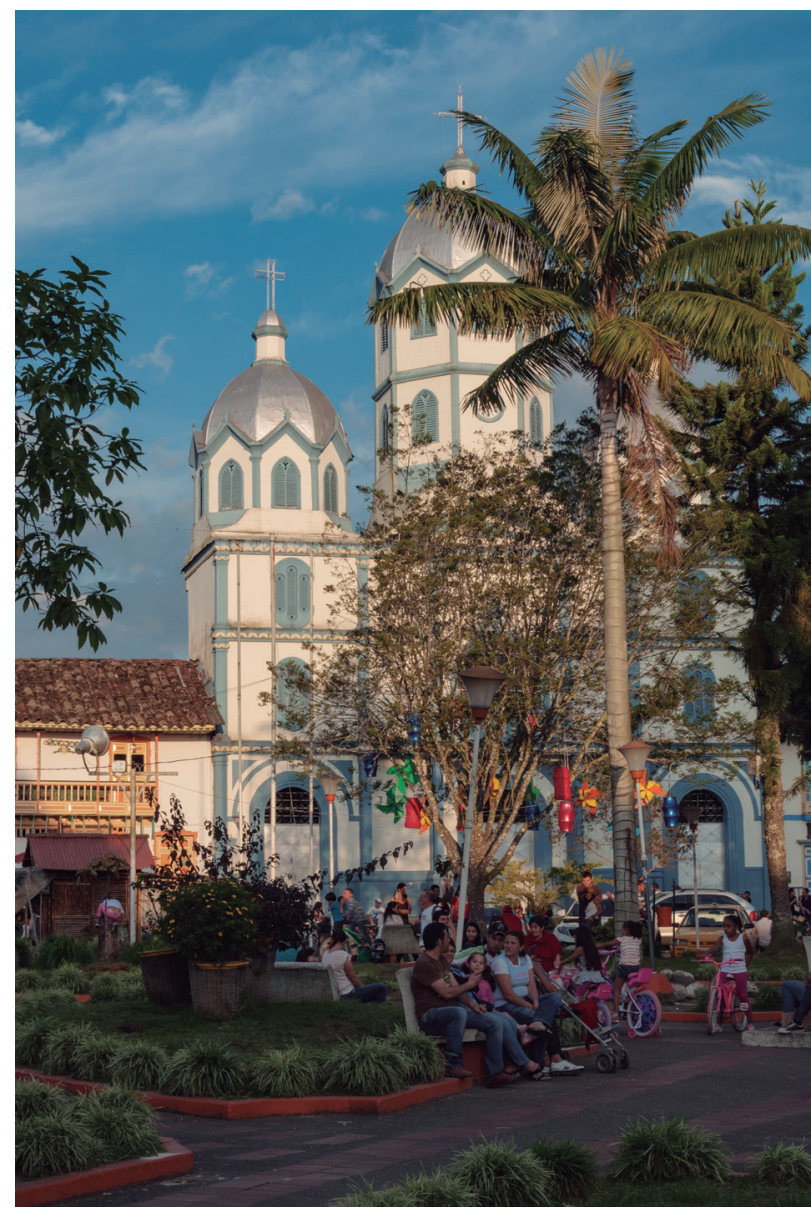

Imagen 2. Parque principal de Filandia, Quindío. Colombia. Pueblo que hace parte del paisaje cultural cafetero declarado patrimonio de la humanidad por la Unesco.

medida un joven quiere permanecer en un lugar realizando la misma actividad que sus padres han hecho durante toda su vida? ¿Cómo conservar las prácticas culturales cuando aquello a lo que han estado vinculadas, su valor y referentes, están desapareciendo? (Imagen 2)

Las decisiones que se toman en un PEMP acerca de estas situaciones tienden en algunos casos a desconocer la realidad y promueven la petrificación de las prácticas y a tomar decisiones sobre las comunidades que las presionan a la inmovilidad y la inacción o a perpetuarlas en la reproducción mecánica de objetos y costumbres que poco a poco pierden su esencia y su razón de ser. En el Paisaje Cultural Cafetero en Colombia se pueden observar, por ejemplo, varias situaciones: las reglamentaciones normativas permiten 
la intervención del territorio con la construcción de conjuntos habitacionales que están alterando el paisaje $\mathrm{e}^{8}$ protegido y por lo tanto obstruyen $\mathrm{y}$ alteran las visuales sobre el territorio que se pretende conservar por sus calidades paisajísticas. Por efectos del turismo, se han sembrado cercas vivas que se utilizan como protección de las fincas y haciendas, aislando los caminos de su contexto y que se convierten en una suerte de túneles verdes para circular, limitando la posibilidad de apreciar e integrarse con el paisaje. Así mismo se fomenta un tipo de arquitectura ${ }^{9}$ que aparece fuera de contexto o que se intenta mimetizar claramente como simulacro y cuya construcción solo utiliza algunos elementos ornamentales para parecer arquitectura tradicional. Las prácticas culturales ligadas a los muchos pueblos de la región cafetera en Colombia recrean situaciones donde «la tradición» y «lo popular» son dos caras de la misma moneda pero con valores muy diferentes. La primera intenta asociarse a una imagen relacionada con la alta cultura, ${ }^{10}$ es decir, lo tradicional por el paso del tiempo sufre un proceso de refinamiento que hace que sus efectos en la cultura puedan ser reconocidos dentro de los cánones del buen gusto. ${ }^{11}$ Mientras, lo popular se mantiene en el terreno de aquello que Ticio Escobar (2003) llama «epistemológicamente híbrido» puesto que los propósitos del arte popular «no están orientados directamente a despertar la emoción estética sino a reforzar, con argumentos formales indiscutiblemente, los muchos cometidos que la colectividad les ha encomendado» (p.287). De acuerdo con el autor, estos productos carecen de reconocimiento como expresiones de refinamiento cultural y por tratarse de objetos y prácticas que provienen de las llamadas «artes aplicadas» son relegadas al dominio de la artesanía, el folklor o la cultura material. Manifiesta Escobar (2003) que la «modernidad hegemónica» no reconoce los productos culturales de lo popular, como expresión artística, debido a que no logran independizar lo estético, no son fruto de la creación

individual, no se producen a través de innovaciones transgresoras y no se manifiestan como obras irrepetibles. Estas divisiones conceptuales tan marcadas, no son reconocidas en los estudios de los PEMP, ni tampoco son analizadas en el contexto de la globalización donde lo que interesa es producir objetos para el consumo que estén revestidos de una aureola de originalidad. Este hecho también tiene su efecto inmediato en la arquitectura, pues lo construido ya no se piensa como una respuesta natural que responde a las condiciones de un lugar para ser habitado, sino como metáfora de una pretendida «identidad $»{ }^{12}$ convertida en mercancía cultural creando escenografías artificiales para las fotografías de los turistas. El mundo globalizado ha fundido en un solo concepto turismo y patrimonio presionando a que la gestión sobre los lugares con interés cultural dependa cada vez más de las economías que provienen del mercado turístico. (Imágenes 3,4)

Una alternativa es que estos hechos sean evaluados desde la dimensión misma que ofrecen los estudios de paisaje en sus diferentes aproximaciones con el fin de proveer herramientas conceptuales para que tanto los impactos como las acciones que se tomen, contribuyan a mitigar el efecto de transformación de aquellos valores naturales y culturales que se quieren preservar para futuras generaciones. El patrimonio

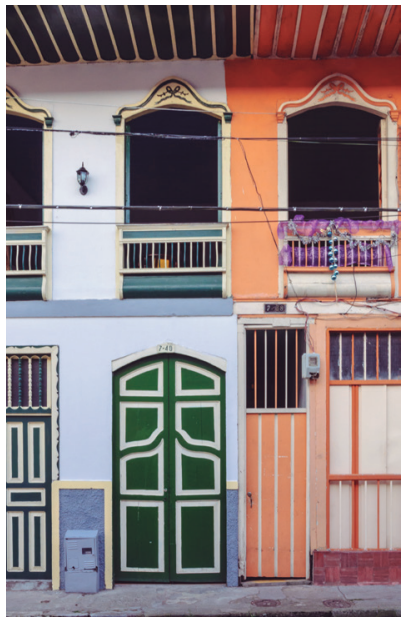

Imagen 3. Arquitectura tradicional de la región. cafetera en Colombia. Filandia, Quindío.

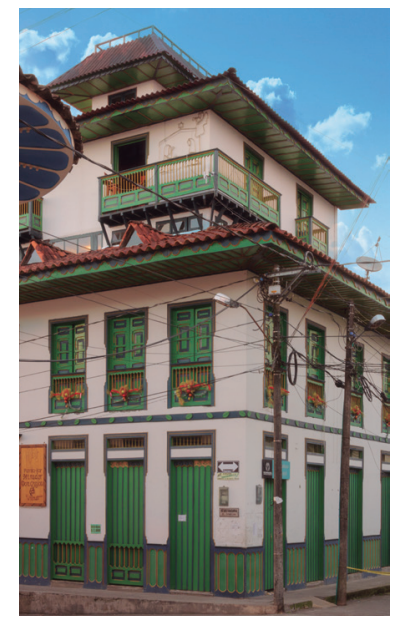

Imagen 4. Arquitectura que imita las construcciones tradicionales en Filandia, Quindío. 
debe entenderse como un factor dinámico y en continuo proceso de reformulación de referentes y contenidos a partir de los cuales las comunidades puedan establecer una hoja de ruta para avanzar y hacer parte del mundo actual sin perder su relación con el pasado y con aquello que consideran sus valores o tradiciones. (Imagen 5)

Una situación similar, pero con otros efectos, es la que sucede en las grandes ciudades y en particular con los barrios denominados de interés urbanístico y arquitectónico, como el caso del barrio La Magdalena en Bogotá, ${ }^{13}$ declarado como sitio de interés urbanístico y arquitectónico dentro del área de Teusaquillo bajo la normativa del Acuerdo 7 de 1979 (1979), donde por primera vez la ciudad protegía sitios con características patrimoniales diferentes al centro histórico. Para mencionar solo dos aspectos que inciden de manera directa en la conservación de estos barrios, se pueden identificar lo imprevisible y lo contradictorio, para dar cuenta de unas lógicas que operan como expresión de unos fenómenos que introducen la variable de lo temporal como un hecho para ser considerado con mayor atención. En primera instancia se puede mencionar lo informal como un hecho característico de las ciudades latinoamericanas, donde los espacios de tiempo en la ocupación, lo esporádico y lo no localizado, aparece ligado a diversas actividades comerciales. Los barrios declarados no escapan a esa condición. En ellos lo informal modifica, altera o se integra con las relaciones de la comunidad propiciando unas prácticas cotidianas que generalmente tienden a ignorarse cuando se analizan estos sectores. Por principio, cualquier intervención sobre el espacio público, sean andenes, avenidas, parques o corredores viales de transporte masivo, apuntan a desaparecer ese tipo de actividad generada por la invasión de lo informal. Lo informal en este caso se asocia a «lo popular» que

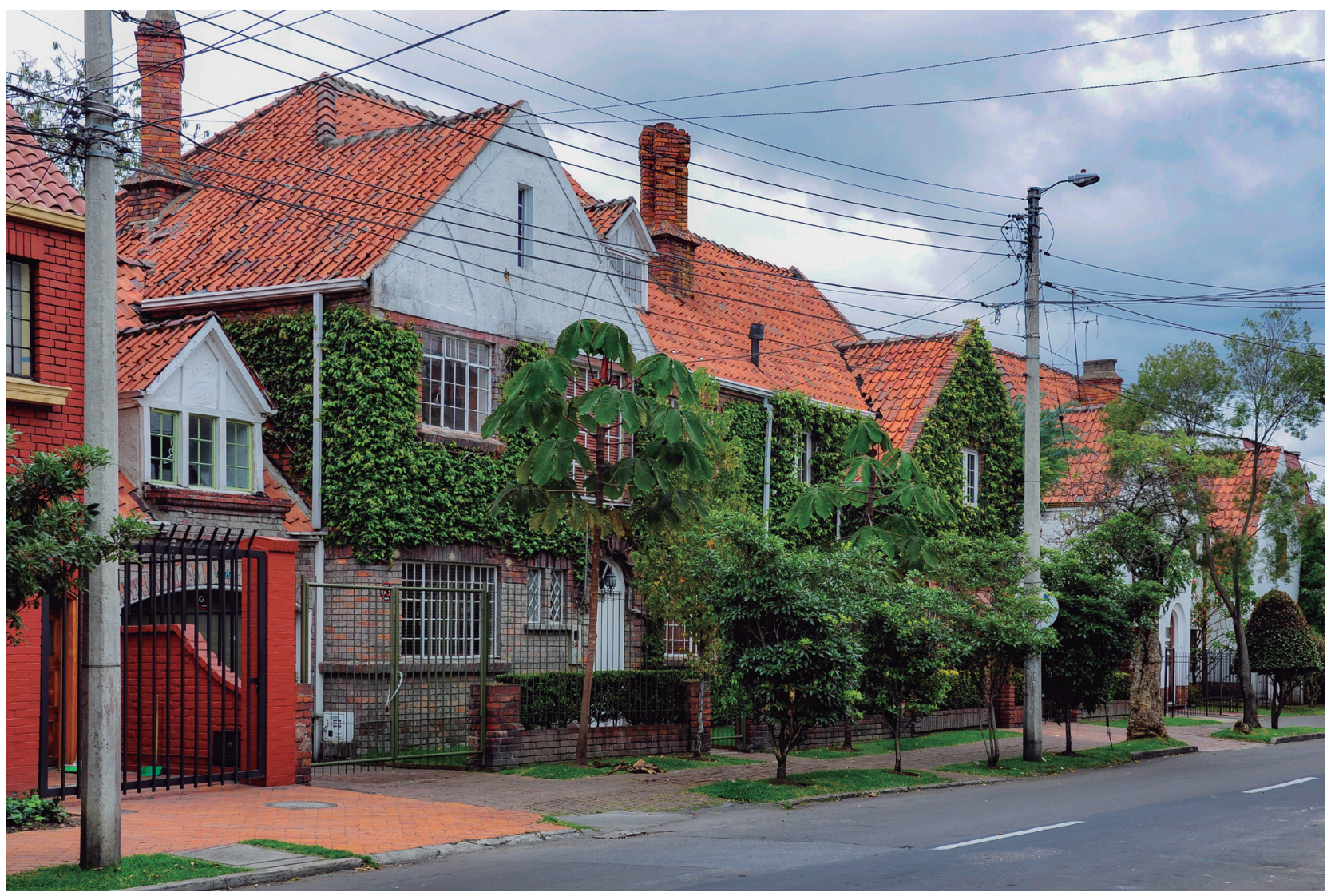

Imagen 5. Barrio La Magdalena, Bogotá. Declarado bien de interés urbanístico y arquitectónico. 
«afea» los sectores patrimoniales introduciendo «ruido» en la apreciación estética a la que apunta su reconocimiento como bienes de interés cultural y que han sido valorados desde consideraciones formales, estilísticas y morfológicas donde prevalece una tendencia a la estetización.

Otro aspecto tiene que ver con las intervenciones mismas en la arquitectura. Un hecho que lleva a pensar cómo se aplica la norma y cuáles son los efectos esperados en el contexto de un barrio de estas características. A diferencia de los centros históricos, estos barrios no cuentan con un acervo histórico en la misma línea de la arquitectura del período colonial. Los hechos de un barrio como La Magdalena están vinculados con historias demasiado personales como para interesar al gran público. Su valor descansa básicamente en un imaginario de ciudad, en los sueños de modernidad de unas clases sociales en ascenso y en un modelo urbano que transforma la ciudad basada en la retícula fundacional por un trazado donde las avenidas, las zonas verdes y los antejardines modifican el paisaje urbano conocido. Al quedar amparado por la norma, se posibilitó la intervención de estos bienes con nuevos usos, actividades y modificaciones. Las valoraciones que sustentaron la declaratoria de este sector de Bogotá en el año 1979 distan de manera considerable del conjunto de elementos de juicio a disposición en el momento actual; hecho que se manifiesta en razón a nuevos procesos de investigación y a que diferentes instituciones, como la Unesco, han ampliado tanto el rango de las clasificaciones como sus contenidos discursivos.

En este contexto, los estudios de paisaje se presentan como una herramienta conceptual y metodológica que aplicada a los procesos de valoración de los lugares intervenidos, sean urbanos o rurales, permiten que las decisiones se complementen y amplíen con las ya conocidas. Este proceso también requiere de un ejercicio donde se apropien los conceptos de paisaje y se reformulen desde la arquitectura para medir su posible aplicación y pertinencia. Ese es el propósito del siguiente planteamiento.
El paisaje como argumento «El paisaje, a partir de ahora, se concebirá como una forma, pero también como una metáfora y como un sistema de signos y de símbolos»

(Nogué, El paisaje en la cultura contemporánea, 2008, p.19)

Autores contemporáneos como Javier Maderuelo (2013), Alain Roger (2007), Joan Nogué (2007) o Agustin Berque (2009) por citar algunos, se han preocupado por develar y localizar culturalmente el nacimiento del paisaje considerando que su origen está vinculado con dos condiciones básicas: de un lado, la contemplación, y de otro, la necesidad de su representación. Berque (2009) va más allá que la mayoría de autores y sitúa el nacimiento del paisaje en la China de las seis dinastías, esto es, hacia la primera mitad del siglo IV. Vincula en este caso, la religión taoísta como el eje estructurante que determinó la relación con la naturaleza al dar valor sagrado a la montaña y erigirla como símbolo de la morada ideal donde prima su conexión con el mito. Pero el paisaje también se entiende como una imagen ${ }^{14}$ que puede definirse en los términos que propone Jean Marc-Besse (2006): Una representación cultural, un territorio producido por las sociedades a lo largo de la historia, un complejo sistémico que articula los elementos naturales y culturales en una totalidad objetiva, un espacio de experiencias sensibles rebeldes a las diversas formas de objetivación y/o como un sitio o contexto de proyecto.

Sin embargo, en estas aproximaciones al paisaje pareciera que aún subyace una visión eurocéntrica en lo que respecta a América Latina. El paisaje de esta gran región pareciera que no se reconoce como un referente de alto valor ni como aporte a la construcción de una noción de paisaje para Europa. El flujo de imágenes y referentes iniciado desde la conquista en una doble dirección producirá un profuso intercambio que alimentará la imaginación de artistas y escritores en ambos continentes tal 
como lo señala Miguel Rojas Mix (1992) en América imaginaria. Un flujo que no termina y que para hoy requiere de reflexiones más profundas. En tal sentido, se deben promover las aproximaciones teóricas que apunten a fortalecer un pensamiento latinoamericano desde y para América Latina ${ }^{15}$ entendiendo sus propias lógicas en el hacer de sus paisajes urbanos, históricos y culturales.

Son muchas las definiciones que pretenden establecer la noción de paisaje. ${ }^{16}$ En el caso de las Ciencias Sociales, existe una preocupación por formular definiciones sobre el paisaje cada vez más precisas para aplicarlas desde sus diferentes disciplinas. Las más utilizadas provienen de la geografía con el fin de entender las dimensiones espacio-temporales de lo que se reconoce hoy como ciudad-región, es decir, lo urbano y lo rural como un tejido indisoluble. Estas aproximaciones al paisaje varían con relación al interés particular de cada disciplina y determinan cómo se describe, interpreta, analiza y valora tanto lo urbano-arquitectónico como las prácticas culturales inherentes a la sociedad que produce esos bienes. Sin embargo, desde una perspectiva más contemporánea, el tema del paisaje aparece como un factor cohesionador para comprender el problema de la ciudad actual enfocado en lo cualitativo.

El paisaje también contempla definiciones para sus diferentes enfoques particulares como pueden ser el paisaje social, el paisaje cultural o el paisaje urbano. Si se habla de paisaje social (2006) su propósito está enfocado con mayor atención en las prácticas y comportamientos sociales. Aunque se consideren muchos otros aspectos, su propósito fundamental es lograr una visión de tipo holístico que permita reconocer tradiciones, herencias culturales o temas de identidad, entre otros. En su mirada confluyen la sociología, la antropología o la geografía social para dar cuenta de un lugar, con una aproximación desde la experiencia, lo sensorial o lo perceptual.
En el caso del paisaje, ${ }^{17}$ su aproximación está estructurada principalmente en lo visual y su soporte conceptual proviene de las mismas disciplinas citadas anteriormente con un énfasis en los conceptos de la geografía. Su definición sigue estando más cercana con el concepto original de paisaje (Desde lo geográfico) y la lectura se propone básicamente a partir de reconocer el lugar mediante estrategias donde los aspectos visuales fungen como un elemento articulador para interpretar, analizar y proponer acciones concretas en el lugar. Existen igualmente las definiciones propuestas por la Unesco como la de paisaje cultural, donde el reconocimiento vincula una actividad económica con los productos y prácticas culturales que otorgan identidad a una comunidad y que mantiene a lo largo del tiempo en condiciones de sustentabilidad. Para la teoría de la arquitectura, este término se asocia de manera más cercana al paisaje urbano, ${ }^{18}$ un lugar que se encuentra configurado por edificios, viviendas, calles y espacios públicos donde las prácticas dan sentido a los lugares. De estos enfoques parte la siguiente propuesta que se enmarca en la necesidad de ampliar el rango de posibilidades para construir procesos de interpretación, análisis y valoración (como proceso metodológico) donde los aspectos cuantitativos, tanto como los cualitativos puedan presentar alternativas de valoración tanto para la arquitectura y el patrimonio, sean estos urbanos o rurales. Dadas las limitaciones en la extensión de este texto, se abordará el tema únicamente a partir de lo que se conoce como «unidades de paisaje» proponiendo una herramienta de descripción, interpretación, análisis y valoración. Es importante aclarar que este ejercicio se encuentra en desarrollo y por lo tanto la propuesta está abierta a debate.

\section{Las unidades de paisaje desde la arquitectura}

El concepto de «unidad de paisaje» tiene un amplio uso en los diferentes estudios que se adelantan sobre paisaje. Su definición se desprende de 
la caracterización, descripción y delimitación cartográfica que define unidades particulares (en términos estructurales, funcionales o perceptivamente diferenciados únicos y singulares) que pueden agruparse de acuerdo con los tipos de actividad, las condiciones geográficas, morfológicas o de productividad (2012). Cada paisaje estudiado puede ser segmentado o separado en diferentes tipos de unidades, lo cual permite sintetizar la caracterización de un territorio e interpretar su funcionamiento y articulación con otras unidades. Este proceso requiere de «la acotación de estas zonas, atendiendo a las transiciones y fronteras que se producen entre diferentes patrones de paisaje» (p.67). Otras definiciones como la de Adriana Gómez y Felipe Londoño (2011) apuntan a considerar el límite visual, en sentido horizontal, la resolución y profundidad de la percepción visual, el relieve o las condiciones atmosféricas, ${ }^{19}$ entre otros, como los criterios para definir una «unidad de paisaje».

Ahora bien, ¿cómo se puede utilizar esta herramienta para caracterizar un sector patrimonial? ¿Se pueden utilizar las unidades de paisaje para reconocer, analizar y evaluar los conjuntos urbanos declarados de interés patrimonial? La respuesta es afirmativa en razón a que muchos de los elementos de la ciudad son equiparables a los que se plantean desde el paisaje y por lo tanto se puede elaborar una herramienta que permita incorporar muchos de estos elementos e interpretarlos desde las disciplinas del urbanismo y la arquitectura. Conociendo la definición de unidad de paisaje, se propone partir de las siguientes modalidades: unidades de paisaje de carácter ambiental, unidades de paisaje de carácter urbanístico y unidades de paisaje de carácter arquitectónico. Existen otras unidades que también tienen aplicación sobre el lugar como serían las unidades de paisaje sociocultural ${ }^{20}$ que pueden superponerse mediante el uso de cartografías con el fin de articular las actividades de los usuarios con el lugar que habitan y lograr una visión de conjunto, pues es una de las apuestas que la categoría de paisaje pretende construir.

Las unidades de paisaje de carácter ambiental permiten registrar el vacío urbano y los elementos relacionados con la estructura ecológica principal, así como sus accidentes geográficos: ríos, quebradas, montañas, valles o reservas naturales. Dan cuenta de los conjuntos naturales (arbolados o no) agrupados en los separadores viales, en los parques, avenidas, antejardines o incluso en los patios de las viviendas. Sirven para reconocer el valor patrimonial de la vegetación y su transformación con el paso del tiempo. Las unidades de paisaje de carácter urbanístico reconocen la estructura económica (usos), así como la estructura funcional y de servicios. Permiten caracterizar aspectos morfológicos, determinar la homogeneidad de los trazados viales y definir sus particularidades como paisajes centrípetos, centrífugos o implícitos ${ }^{21}$ (2011). Perfilan las tendencias de los usos y hacen evidentes los lugares de mayor vulnerabilidad o cohesión. Las unidades de paisaje de carácter arquitectónico definen y agrupan los grupos de edificaciones como unidades conceptuales. Esto quiere decir que su caracterización se lleva a cabo analizando los elementos del lenguaje arquitectónico que comparten así como la homogeneidad en términos de alturas, perfiles y uso del color. ${ }^{22}$ Así mismo, se pueden determinar los elementos en conflicto ya sea asociados a una misma edificación o como elementos disruptores dentro del contexto de un grupo de edificaciones.

Las unidades de paisaje deben ser registradas mediante el diseño de fichas donde se consigne la información que se debe ir clasificando de acuerdo con los parámetros establecidos. Esto permite que los datos recolectados de un barrio o sector de ciudad queden consignados en cartillas de fácil consulta. Igualmente pueden ser utilizados como cartografías donde se crucen los diferentes tipos de datos recogidos y 
que sea de interés para el investigador. El proceso de lectura para las diferentes unidades de paisaje comprenden básicamente los siguientes pasos: ${ }^{23}$ descripción, interpretación, análisis y valoración. Este procedimiento se justifica en tanto demuestra que la valoración puede abordarse desde una instancia donde los componentes no son evaluados únicamente por sus características formales (o estilísticas, dado el caso), sino como conjuntos relacionales y conceptuales donde se comparten enfoques comunes mediante la asignación de atributos. Una vez cruzada esta información con las de las unidades de paisaje social, se evidenciará cómo las prácticas sociales dan cuenta de una manera de hacer, de ver y percibir la vida en sus productos culturales (en este caso el urbanismo y la Arquitectura). La variable temporal, en razón a las múltiples intervenciones a que están expuestas estas arquitecturas (a pesar de la norma que restringe estas acciones) permite entender el objeto en sus diferentes dimensiones, conflictos, posibilidades y potencial. En el grupo de variables y atributos propuestos por los estudios de paisaje existen algunas que ya se han trabajado en otras investigaciones ${ }^{24} \mathrm{y}$ pueden identificarse como: patrones de paisaje, recursos paisajísticos ${ }^{25}$ o conflictos paisajísticos (2012) así como las cualidades visuales donde el ángulo de visión, la cuenca visual o la fragilidad y la vulnerabilidad (2011), pueden incidir en las decisiones sobre los tipos de intervención.

Como puede observarse, los estudios de paisaje reconocen variables enfocadas básicamente en lo visual (lo cual es una de sus características), pero existen tantos componentes como elementos identificables en el paisaje. Por tanto, corresponde al investigador definir los que son de su interés en la formulación de una propuesta de planificación y gestión. Un aspecto de relevancia tiene que ver con lo que se conoce como escala visual de percepción y relación, la cual se refiere a los paisajes centrípetos, centrífugos o implícitos (Gómez \&
Londoño, 2011). Esta aproximación es de gran utilidad en la medida que permite hacer lecturas y propuestas con una comprensión del lugar que reconoce las direccionalidades, fugas y flujos principalmente en los espacios públicos, para la reformulación de las actividades del lugar cuando es intervenido. En cuanto a la interpretación y análisis, las categorías pueden agruparse a partir de los componentes visuales y temporales, las secuencias visuales, los patrones de color así como los conflictos visuales y ambientales relacionados con la fragilidad visual y la vulnerabilidad.

\section{Conclusiones}

En términos generales puede decirse que una aproximación desde la noción de paisaje abre mayores perspectivas en el reconocimiento de los lugares donde se intenta realizar algún tipo de exploración, valoración o intervención. Es claro también que cualquier procedimiento de esta naturaleza debe abordarse desde una perspectiva multidisciplinar e interactuar directamente con las comunidades, quienes, en últimas, son las más afectadas por las decisiones que surjan como producto de cualquier propuesta de gestión e intervención. Sin embargo, como propuesta de investigación desde la academia (para profesionales y estudiantes), es un aporte para que, mediante su aplicación, se logren mayores niveles de sensibilización frente a las lecturas de la ciudad. En este sentido, debe abordarse el problema de la valoración patrimonial mediante estrategias de mayor complejidad donde pueda evidenciarse el reconocimiento real de una sociedad, su cultura, los valores patrimoniales y los tipos de prácticas que son en realidad los que dan sentido y valor simbólico a los lugares. El trabajo con las comunidades es esencial para establecer los horizontes de sentido y la pertinencia de mantenerse atados a unas prácticas y a unos productos que requieren ser entendidos más allá de su valor simbólico, es decir, como posibilidad de transformación y 
cambio por las presiones de las velocidades y los tiempos. El vínculo, tan promocionado hoy por los gobiernos de turno, entre turismo y patrimonio requiere de una crítica consistente para insistir en los riesgos de caricaturizar sus comunidades. Es necesario igualmente fortalecer los procesos de investigación mediante la implementación de metodologías que recojan el espíritu y vocación de los lugares habitados y que, desde la experiencia con ese lugar, tanto el investigadores como los estudiantes, logren una mayor comprensión de las dinámicas en las que están envueltas las ciudades actuales.

Esta propuesta, aún en construcción, se fundamenta en la necesidad de abordar los problemas de la ciudad latinoamericana actual proponiendo nuevas herramientas argumentativas con el fin de fortalecer y ampliar la discusión en el campo de la historia, la teoría y la crítica. La discusión también debe centrarse en determinar si los discursos acerca del patrimonio todavía se encuentran permeados por esa mirada eurocéntrica mencionada anteriormente, en particular cuando el patrimonio de las ciudades latinoamericanas se sigue considerando como algo de menor valía y por otro lado, en la incidencia de la globalización que emerge con un factor homogeneizador que

\section{Referencias}

Augé, M. (2003). El tiempo en ruinas. Barcelona: Gedisa, editores.

Besse, J.-M. (2010). La sombra de las cosas. Sobre paisaje y geografia. Madrid: Biblioteca nueva.

DAPD, D. A. (1979). Acuerdo 7. Bogotá: DAPD.

Gómez, A., \& Londoño, F.C. (2011). Paisajes y Nuevos Territorios (En Red). Barcelona: Anthropos editorial.

Gutierrez Aristizábal, A. (2019). Paisaje social construido en el barrio La Magdalena de Bogotá 1920-2012. Modelo de aproximación histórico-crítico. Bogota: Universidad La Gran Colombia.

Maderuelo, J., \& (Ed). (2006). Paisaje y pensamiento. Madrid: Abada Editores. afecta a los países de América Latina al presionar a que sus ciudades oferten en el mercado global sus lugares patrimoniales que tienden a convertir los valores culturales en simulacros que son representados en escenografías o en parques de diversiones. ${ }^{26} \mathrm{Al}$ convertir el patrimonio en mercancía, se despoja a las comunidades de la posibilidad de que sus tradiciones fortalezcan el tejido social que en muchos casos es frágil y que en otros se encuentra muy poco cohesionado o desarticulado. Mediante el reconocimiento por unidades de paisaje se logra configurar un escenario más complejo donde se hacen evidentes las interrelaciones entre prácticas socioculturales y lugar. Los valores cualitativos adquieren aquí un gran peso y en la confluencia de estos factores, al combinar percepción y experiencia con los valores cuantitativos, se pueden reconocer los distintos matices que dan verdadero sentido a los lugares patrimoniales.

La presente propuesta intenta reconocer, apropiar y reformular para la disciplina, nuevas herramientas metodológicas y conceptuales que contribuyan a la construcción de una mirada holística donde sociedad, cultura y ciudad se fundan en una realidad en la que el patrimonio se articule en un presente dinámico y sostenible para las futuras generaciones.

Muñoz, A. (2012). Guía metodológica. Estudios de paisaje. Valencia, España: Consellería de Infraestructuras, Territorio y Medio Ambiente.

Nogué, J. (2008). El Paisaje en la cultura contemporánea. (J. Nogué, Ed.) Madrid, España: Biblioteca Nueva, S.L.

Nogué, J., \& Romero, J. (2006). Las otras Geografias. Valencia: Tirant Lo Blanch.

Pisón, E. M. (2009). Miradas sobre el Paisaje. Madrid: Biblioteca Nueva.

Roger, A. (2007). Breve tratado del Paisaje. Madrid: Biblioteca Nueva, S.L.

Rojas Mix, M. (1992). América imaginaria. Barcelona: Lumen. Xirau, R. \&. (2003). Estética. Madrid: Editorial Trotta, S.A. 


\section{Notas}

${ }^{1}$ Esta reflexión hace parte de dos investigaciones. Una ya terminada y próxima a publicarse denominada Paisaje social construido en el barrio La Magdalena en Bogotá. 1920-2012. Modelo de aproximación histórico crítico (2019) y otra que se encuentra en proceso: La planificación territorial de Bogotá entre paradojas y discursos. Caracterización del paisaje urbano de los Barrios Las Nieves y Usaquén (2000-2018) Ambas adelantadas por el autor como docente investigador en la Facultad de Arquitectura de la Universidad La Gran Colombia en Bogotá.

${ }^{2}$ Tal es el caso de ciudades como Medellín en Colombia o Curitiba en Brasil.

${ }^{3}$ También es claro que la norma pretende actuar como herramienta para instrumentalizar un modo de pensamiento o un tipo de discurso patrimonial. En términos generales la norma deriva de una conceptualización del patrimonio y es su impronta valorativa y operativa sobre aquello que debe ser conservado.

${ }^{4} \mathrm{El}$ recurso del grafiti como expresión de inconformidad, rebeldía o simple vandalismo marca los objetos de la ciudad, patrimoniales o no, dejando una sensación de abandono y descuido, así desde otras miradas estas acciones se consideren con algún tipo de valor artístico. Muchas de estas intervenciones son promocionadas por los mismos entes gubernamentales de la ciudad, con el fin de potenciar la participación ciudadana, en este caso con grupos de jóvenes, para fortalecer el sentido de pertenencia con relación a la ciudad.

${ }^{5}$ Esta reflexión como parte del trabajo de investigación en proceso que adelanta el autor de este texto en la Universidad La Gran Colombia en Bogotá denominado La planificación territorial de Bogotá entre paradojas y discursos. Caracterización del paisaje urbano de los Barrios Las Nieves y Usaquén (2000-2018).

${ }^{6}$ En este sentido Marc Augé (2003) hablando de la ruina dice: «La contemplación de las ruinas nos permite entrever fugazmente la existencia de un tiempo que no es el tiempo del que hablan los manuales de historia o del que tratan de resucitar las restauraciones. Es un tiempo puro, al que no puede asignarse fecha, que no está presente en nuestro mundo de imágenes, simulacros y reconstituciones, que no se ubica en nuestro mundo violento, un mundo cuyos cascotes, faltos de tiempo, no logran ya convertirse en ruinas. Es un tiempo perdido cuya recuperación compete al arte».

${ }^{7}$ En el marco de la instalación del I Congreso Internacional de Turismo Rural, llevado a cabo en la ciudad de Armenia en septiembre de 2015, el concejal Luis Fernando Ramírez Echeverry manifestó con relación a las amenazas al Paisaje Cultural Cafetero declarado por la Unesco Patrimonio de la Humanidad que: «Hay varios elementos que atentan contra el paisaje a los que se les debe prestar mayor atención... Factores ampliamente conocidos como el relevo generacional, ya que los jóvenes de hoy no quieren trabajar en el campo; el crecimiento desmedido e indebidamente planificado de nuestras ciudades está atentando contra la frontera agrícola, contra la seguridad alimentaria. Tenemos que revaluar los Planes de Ordenamiento Territorial, POT, articularlos a la declaratoria y lanzar un SOS porque podemos quedarnos sin la declaratoria».

Tomado de www.lacronicadelquindío.com el 25 de septiembre de 2015.

${ }^{8}$ El Plan de Ordenamiento Territorial POT presentado para el municipio de Armenia fue premiado en la Bienal de Arquitectura Colombiana de 2010. El documento denominado Armenia una ciudad de oportunidades para la vida, fue elaborado por la Alcaldía a través de la Secretaría de Planeación Municipal a cargo de José Ignacio Rojas Sepúlveda y con la dirección del arquitecto Marco Antonio Ramírez. De acuerdo con las consideraciones del jurado calificador, se resaltó que la bitácora del municipio «Le apuesta por ordenar el territorio de manera compacta lo que ha permitido potenciar lo existente y ha optimizado, acertadamente y con rigor, la calidad de vida de los ciudadanos». Publicado el 25 de mayo de 2010 de www.lacronicadelquindío.com

${ }^{9} \mathrm{Se}$ hace referencia a la arquitectura que se construyó hacia finales del siglo XIX durante el período denominado de la Colonización Antioqueña. En este sentido, pueblos como Salento en el Departamento del Quindío, se venden con una arquitectura de reciente construcción que se mimetiza con la tradicional sin que los visitantes tengan conciencia de las diferencias entre ambas. Así mismo sucede en otros pueblos declarados patrimonio en Colombia como es el caso de Villa de Leyva en el Departamento de Boyacá.

${ }^{10}$ En este sentido puede situarse el propósito que instituciones como Artesanías de Colombia juega en el contexto del manejo de la artesanía colombiana al despojarla de su carácter «popular» y convertirla en objeto de la alta cultura desmaterializando sus significados y reformulando sus efectos como producto cultural para el consumo turístico.

${ }^{11}$ Algunas de las prácticas ligadas a la tradición son apropiadas por las élites que establecen patrones de diferenciación en cuanto a lo festivo, lo gastronómico o la moda.

${ }^{12}$ Una identidad construida a partir de las exigencias que la declaratoria promueve.

${ }^{13}$ El Barrio La Magdalena de Bogotá fue construido en las décadas de los años treinta y cuarenta del siglo XX bajo un modelo urbano que promovió la construcción de avenidas, boulevares, andenes con áreas verdes y un modelo de casa compacta con antejardín y patio posterior. 
${ }^{14}$ De acuerdo con Alain Roger (2007) el nacimiento del paisaje se consolida en la pintura del Renacimiento y en particular en las obras de los pintores flamencos como Roger Campin, entre muchos otros.

${ }^{15} \mathrm{Al}$ respecto vale la pena anotar el aporte a la construcción de un pensamiento latinoamericano para la disciplina desde los Seminarios de arquitectura Latinomericana SAL.

${ }^{16} \mathrm{El}$ Convenio Europeo del Paisaje (Florencia 20/10/2000) lo define así: por «paisaje» se entenderá cualquier parte del territorio tal como la percibe la población, cuyo carácter sea el resultado de la acción y la interacción de factores naturales y/o humanos.

${ }^{17}$ Tomado de la geografía principalmente.

${ }^{18}$ Existen dos textos que tratan este tema de manera particular: «El paisaje urbano» de Gordon Cullen y «La imagen de la ciudad» de Kevin Lynch.

${ }^{19}$ Existen otros elementos desde lo visual como son: cuenca visual, ángulos de visión, profundidad del paisaje, visibilidad, atmósfera y luz, fuerza visual, perturbación visual o coherencia paisajística entre otros.

${ }^{20}$ Las unidades de paisaje sociocultural hacen referencia a las actividades ligadas a las comunidades donde se recogen las experiencias, permanencias, ocupaciones y demás actividades relacionadas con las prácticas socio-culturales de acuerdo con el tipo de investigación que se pretenda adelantar.

${ }^{21}$ Más adelante se aclara la importancia de estos tres tipos de paisaje.

${ }^{22} \mathrm{El}$ reconocimiento de una paleta de color, ya sea por afinidad cromática o por contraste, posibilita llevar a cabo intervenciones de menor impacto visual y que reconozcan el lugar vinculando tanto la materialidad (tectónica) como el uso de valores cromáticos en concordancia con el contexto. Este recurso también debe aplicarse en las unidades de paisaje de carácter ambiental.

${ }^{23}$ Esta propuesta metodológica se plantea de manera general. Es claro que para cada lugar se requerirá de una metodología que se estructure con base en las necesidades y objetivo específico de cada investigación.

${ }^{24}$ Es el caso de estudios como Paisaje y nuevos territorios (en Red) Cartografías en interacciones en entornos visuales y virtuales (2011) o la Guía metodológica Estudio de Paisaje (2012). Ambos trabajos se enfocan en los aspectos visuales, paisajísticos y de gestión del paisaje. El primero en la ciudad de Manizales, en Colombia y el segundo, como un documento guía para las poblaciones de la Comunidad Valenciana en España. Parte de este trabajo se fundamenta en la investigación adelantada por el autor denominada Paisaje social construido en el barrio La Magdalena de Bogotá 1920-2012. Modelo de aproximación histórico-crítico (2019) próxima a publicarse. Actualmente adelanta la investigación.

${ }^{25}$ De acuerdo con Arancha Muñoz (2012) «Son los elementos o puntuales singulares de un paisaje o grupo [...] que definen su individualidad y que tienen valor visual, ecológico, cultural y/o histórico» (p.78).

${ }^{26}$ Tal es el caso del Parque del Café en el departamento del Quindío, Colombia que hace parte del Paisaje Cultural Cafetero declarado patrimonio cultural de la humanidad por la Unesco.

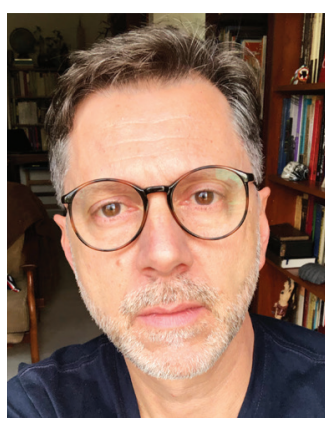

\section{Alonso Gutiérrez-Aristizábal}

Arquitecto, docente e investigador en temas de ciudad enfocados en la teoría, la historia, el diseño, la crítica, el paisaje y el patrimonio. Candidato a Doctor de la Universidad Nacional de Colombia en el Doctorado de Arte y Arquitectura en su Línea de Estética y Crítica. Magíster en Historia y Teoría del Arte, la Arquitectura y la Ciudad de la misma universidad.

Ha trabajado con entidades públicas y privadas en cargos administrativos, proyectos de diseño, presupuestos de obra y licitaciones. Se ha desempeñado como docente en la Universidad Nacional de Colombia y en la Universidad Piloto. Actualmente se encuentra vinculado como profesor investigador de tiempo completo de la Facultad de Arquitectura de la Universidad La Gran Colombia donde hace parte del grupo de investigación en la línea de Gestión del Hábitat Territorial. Hace parte también de los grupos de investigación Poéticas intertextuales, Arte, Diseño y Ciudad y del Observatorio de Arquitectura Latinoamericana Contemporánea ODALC ambos en la Universidad Nacional de Colombia. 